\title{
Towards Ethics in Information Systems
}

\author{
Flávia Maria Santoro (D) [ Universidade do Estado do Rio de Janeiro | flavia@ime.uerj.br ] \\ Rosa Maria E. Moreira da Costa (D) [ Universidade do Estado do Rio de Janeiro | rcosta@ime.uerj.br ]
}

\begin{abstract}
Information Systems (IS) play an essential role in shaping almost all sectors of society, such as commerce, politics, services, entertainment, information, relationships, among others. Digital technologies have enabled a new dimension of products, transmission, storage, and access to information. The outcome of this whole transformation process is intended to provide improvement and facilitating the lives and practices of individuals in society. However, we have also to face its negative impacts. We argue that situations involving both the design and the adoption or use of IS, should be analyzed from the point of view of Ethics through a well-defined process that might help the professional and/or citizen in making decisions in sensitive contexts when conceptual conflicts show up. To justify the definition of this process, we discuss the significance of new technologies based on Andrew Feenberg's Philosophy of Technology. Grounded on this theory and based on the initial related discussions we highlight the benefits and problems of the new technologies in the contemporary world. Finally, we present the process proposal and analyze the results of its application in the context of two well-known real cases and discuss the results considering the theoretical foundation.
\end{abstract}

Keywords: Ethics, Information Systems, Method, Process

\section{Introduction}

From the 1980s onwards, we observed the development and popularization of digital multimedia artifacts, cell phones, video games, communication technologies, and the Internet. More recently we have noticed the great movement of digitalization of businesses, as well as the expansion of Artificial Intelligence and processing of large volumes of data. By the end of the first decade of the 2000s, Kohn and Moraes (2007) already indicated that society was moving through what was conventionally called the Digital Age. In this scenario, Information Systems (IS) play an essential role in shaping almost all sectors of society, such as commerce, politics, services, entertainment, information, relationships, among others. Digital technologies have enabled a new dimension of products, transmission, storage, and access to information. The outcome of this whole transformation process is intended to provide improvement and facilitating the lives and practices of individuals in society. However, there are also clear side effects.

Our social relationships are being increasingly influenced by the Internet, smartphones, digital television, etc., but we face both positive and negative impacts. Whether these features at the same time offer attractive possibilities, on the other hand, they contribute to progressively stimulate virtual relationships. Mobile devices have opened new communication possibilities to build networks of research and friendships, facilitating access to a plethora of information. However, frequently this comes with privacy invasions and information overload or with feelings of dependence on these resources.

Computer technology is genuinely revolutionary because it is "logically malleable" as computers can be programmed to perform any activity characterized in terms of inputs, outputs, and logic operations (Moor, 1985). Since logic applies to everything, the computational technology functions seem to be unlimited. According to Moor (1985), the "computer revolution" occurred in two stages: the first one was the technological introduction, in which technology was developed and refined; it took place already in the first 40 years after the Second World War; and the second one was the technological permeation in which technology has been integrated into regular daily human activities and social institutions, changing the actual meaning of traditional institutions such as money, education, work or democracy. Thus, a distinct ethical discussion is needed.

Moor (1985) proposes a broad and comprehensive definition of Computational Ethics, which is independent of a specific philosophical theory and at the same time compatible with a wide variety of approaches to solving ethical problems. For the author, there is a political gap in how Computational Ethics should be used. Computing gives us novel features, and, in turn, they give us new opportunities for action. Often there are no policies to support dealing with some of these situations, or the existing policies seem inappropriate. Focusing on Information Systems (IS), a central task would be to determine what we should do in those cases, i.e., to formulate strategies to guide our actions. Another difficulty is that, although a problem in Information Systems Ethics may initially seem clearly expressed, a deeper understanding may reveal conceptual conflicts. Such cases require analyses to provide a coherent conceptual framework within which it would be possible to formulate proper policies.

In a more recent paper, published years after the 1985 seminal, Moor (2020) suggested three ways to improve our ethical approach to technology. First, we need to consider that ethics is a continuous and dynamic enterprise. Thus, every time a new technology appears, there must be a concern to consider ethics. Second, we need to establish better collaborations between ethicists, scientists, social scientists, and technologists, i.e., to work in a multidisciplinary approach. Ethicists need to be knowledgeable about the nature of technology to formulate an empirical basis describing what are, and what are not, the 
consequences of the development and use of such technology. Third, we need to develop more sophisticated ethical analyzes. Ethical theories themselves are often simplistic and do not give much guidance to particular situations. Frequently the technological assessment is made in terms of cost/benefit, ignoring, or diminishing moral values that are difficult to represent or translate into financial/monetary terms.

We argue that situations involving both the design and the adoption or use of IS must be analyzed from the point of view of Ethics through a well-defined process that can help professionals and/or citizens in decision-making in contexts that have conceptual conflicts. This would allow the development of ethical systems as well as the usage of them in an ethical approach. To justify the definition of this process, we discuss the significance of the new technologies based on Andrew Feenberg's Philosophy of Technology (Dusek, 2006). Grounded on this theory, we highlight the benefits and problems of the new technologies in the contemporary world. Finally, we present the process proposal and analyze the results of its application in the context of two well-known real cases and discuss the results considering the theoretical foundation.

This paper is an extension of the paper published in WICS 2020 (Santoro, 2020) and is organized as follows. Section 2 presents the background knowledge, including a discussion about the details of the contemporary technologies that emerge with ethical problems. Section 3 describes related work. Section 4 presents the proposed process. Section 5 reports two case studies to illustrate the application of the proposed process. Section 6 discusses the results in the light of the theory presented before, and Section 7 concludes the paper with final remarks.

\section{Background Knowledge}

Nowadays, it is hard to think of humankind without technology. Technology seems to be a central element in determining our evolution as humans. However, what is the meaning that we give to technology in our life? Is the importance of a specific technology associated with the significance we give to it?

Feenberg (2013) explains that there is an important distinction related to what the Greeks called physis and poiesis. Physis is translated as nature. The Greeks understood nature as something that emerges from itself. Poiesis is the activity of 'making'. It occurs when men produce something, the so-called artifacts; everything from art, crafts, to social contracts. The word techne, which is in the origin of the modern word's "technique" and "technology", means the knowledge or discipline associated with a form of poiesis. For the Greeks, each techne guides the production of an artifact, associating it with purpose and meaning. Although artifacts depend on human activity, the knowledge contained in techne is not subject to opinion or intention. So, the purpose of artifacts also shares objectivity since they are defined by techne.

Another important distinction is between existence and essence. According to Feenberg (2013), existence answers the question of whether something is or is not; yet the essence answers the question of what the thing is. The essence of natural things includes a purpose, and as well the essence of artifacts does. Therefore, humans are not the heads of nature, but they work with their potential to bring forth a meaningful world. Knowledge about the world and the human action over it is not arbitrary but the realization of what is hidden in nature. Feenberg (2013) concludes that the Greeks interpreted the being as such through the concept of technical fabrication. Technology occupies an inferior position in the high culture of modern societies, but it was, in fact, already at the origin of this culture and, according to the Greeks, it holds the key to the understanding of being.

René Descartes and Francis Bacon, the founders of modern thought, were responsible for a shift in this scenario: Descartes stated that, through science, man is master of nature, and Bacon claimed that "knowledge is power". The meaning and ends of things are something that human creates and not what she/he discovers. In the modern era, technology was understood as purely instrumental and value-free. The instrumentalist philosophy of technology prevails as a product of civilization, unwittingly assumed by most people. Technology, in this context, treated nature as raw material to be controlled and used. In the $19^{\text {th }}$ century, modernity arrived with progress toward the satisfaction of human needs towards technological advancement. For Feenberg (2013), the question that arises is "for what purposes?". The author states that this issue brought about a crisis of civilization to which there is no way out: "we know how to get there, but we do not know why we are going, or even to where". So, it was not clear what damage was attributed to technology. Nevertheless, in the $20^{\text {th }}$ century, with the advent of world wars and environmental catastrophes, it was no longer possible to ignore the lack of meaning of modernity.

Feenberg (2013) organized the lines of thinking about technology and summarized those views, according to Table 1. The author classifies the technology through two axes that reflect the relationship with human value, and control. The vertical axis presents either technology value as neutral, as the Illuminism assumed, or technology with value-added, as the Greeks thought. On the horizontal axis, the technology is considered autonomous or humanly controllable. Autonomous technology does not mean that it works by itself; the human being is involved, but the question is whether they have, in fact, the freedom to decide how the technology will be developed. On the other hand, technology can be humanly controllable, while the next step of evolution can be determined according to our intentions. Four quadrants stand out.

Considering the statements in Table 1, we can attribute meaning to technology under different theoretical frameworks. Additionally, there will always be counterpoints between the benefits that a technology can potentially bring to society and the harm it can cause.

Instrumentalism (human control and value neutrality) is the modern view, where technology is simply a tool or instrument of the human being with which she/he meets her/his needs. This perspective is linked to the "faith in 
progress" as a dominant trend in Western thought until very recently. Determinism (autonomy and value neutrality) is a vision that comes from the social sciences, which states that technological advances move history. In this context, technology is not controlled by the human being, but instead it controls the human being, that is, "it shapes society to the demands of efficiency and progress". It is not up to the human being to adapt technology to his desires, but, on the contrary, the human being must adapt to technology as an expression of humanity.

Table 1. Lines of Thought about Technology

\begin{tabular}{|c|c|c|}
\hline Technology is ... & Autonomous & Human-controlled \\
\hline \begin{tabular}{lr}
\multicolumn{2}{l}{ Neutral } \\
Separation \\
between means \\
and & ends, \\
reference & to \\
Iluminism &
\end{tabular} & $\begin{array}{l}\text { Determinism } \\
\text { For example, } \\
\text { theory of } \\
\text { modernization }\end{array}$ & $\begin{array}{l}\text { Instrumentalism } \\
\text { Liberal faith in } \\
\text { progress }\end{array}$ \\
\hline $\begin{array}{l}\text { Value-added } \\
\text { Means form a } \\
\text { way of life that } \\
\text { include ends, } \\
\text { reference to } \\
\text { Greek though }\end{array}$ & $\begin{array}{l}\text { Substantivism } \\
\text { Means and end } \\
\text { connected } \\
\text { systems }\end{array}$ & $\begin{array}{l}\text { Critical Theory } \\
\text { Choice for alternative } \\
\text { means-end systems }\end{array}$ \\
\hline
\end{tabular}

While the thesis about neutrality assigns a merely formal value to technology - the efficiency for improving human life in general - Substantivism (autonomy and assigned substantive value) attributes substantive values to technology that technology is not neutral. A substantive value involves a commitment to a specific conception of a "good life". The use of technology for a particular purpose is itself a choice. Technology is not simply instrumental in any value a person has; it already brings value with it. Determinism is similar but usually optimistic. Marx and postwar modernization theorists believed that technology was the neutral servant of basic human needs. In turn, for Substantivism, the autonomy of technology is a threat. Heidegger (2007) is one of the great substantivism theorists of the 20th century, pointing to the characteristic of modernity as the triumph of technology overall values. Critical Theory (human control and assigned substantive value) recognize the harmful consequences of technological development highlighted by Substantivism but still believes in a promise of greater freedom in technology. The problem is not with technology as such, but with the failure of the human being, up to this date, to invent appropriate institutions to practice human control over it.

In the Computing area, and particularly in Information Systems, several issues emerge affecting both the professional as well as their clients and/or employers. In general, the literature (Bowyer, 2000) categorizes those issues in the following topics: systems development, automation of decision, violation of information, Internet, and critical systems.

The development of systems involves both the professional's responsibilities towards the customer to guarantee the delivery of a product suited to their expectations, with the agreed quality, as well as the participation and interaction of the customer in the definition of the product value they want to receive. One of the most significant factors is conducting assessments throughout the development process. On the part of the employer, it is expected to provide necessary conditions for the success of the development process.

One of the purposes of an information system is to support decision-making at the various hierarchical levels of an organization. However, this can be done in several ways, and there are possibly different levels of automation of these decisions. Some factors to be considered are how to ensure the best task distribution between the user and the system and the availability of correct content for user decisionmaking.

The violation of information is related to the spread of viruses and hackers. A virus is a program that can make copies of itself and can host itself in other programs, generally causing some damage to the system or data (Masieiro, 2013). A hacker is a person who accesses any computer system without authorization through computer networks (Masieiro, 2013). Thus, it is necessary to be concerned with information security, that is, to guarantee and respect data confidentiality levels, as well as the security of data circulation (protection against intrusions and undue access, and damage to data and systems).

Concerning the Internet, both professionals and users have several ethical responsibilities. The first one, we stress matters of the websites whose content must be maintained, guaranteeing the truth and quality of the information. In addition, for business or e-commerce applications, the integrity of transactions and defined rules must be implemented by computer professionals, assuring that the processes will be recognized by their users.

Critical systems are those whose failures can cause severe harm, like, death or grave damage to the environment, for example, aircraft control systems and medical equipment. In this case, a strict development process, evaluation techniques, and tests are needed to ensure that these products are safe for all layers of society and the environment involved.

In 2000, Bynum (2000) anticipated some issues, arguing that because of the invention of "life-imitating" machines, there would be dramatic changes in social policies and practices in law, economics, and human relations. Consider, for example, some of the economic implications of computerized automata. The development of such machines "gives the human race a new and more efficient collection of mechanical slaves to do their work". Nowadays, we observe that robots effectively eliminate many human jobs, rendering people useless in the labor market. Even the intellectual work of the human brain is not immune to replacement by machines.

Underlying these problem categories, we underline three types of current technologies. As so, in the next sections, we discuss the advantages and disadvantages of three contemporary technologies that have been permeating many aspects of our daily life and are shaping the near future a society: Internet, Artificial Intelligence and Big Data. 


\subsection{The Growth of Internet and its Social Networks}

The Internet is one of the most relevant technologies of the so-called "Information Age" or "Digital Society". Sociocultural changes are observed in terms of work environment, family, entertainment, and leisure. In general, social networking is currently the preferred platform for all sorts of activities, both for business and personal, and sociability has significantly increased. It is clear the migration of businesses (electronic businesses), government (electronic government), and civil society in general to social networks. Moreover, relevant political movements have started from social networks, for example, the Arab revolutions against dictatorships and protests against the management of the financial crisis. There are innumerable benefits of the Internet, such as access to information, new business models, increased communication possibilities, tools to support learning, among many others. Figure 1 illustrates the benefits and problems related to the Internet and its applications. The green arrows point to the benefits that Internet brings, such as being capable of transforming companies as well as shortening distances between people and providing access to information; however, the red arrows highlight that, at the same time, it decreases privacy and produces information overload.

The democratization of access to information has never been more publicized and promoted than in the Internet era. The most frequent propaganda is about individual freedom as far as content is supposed to be "personalized". However, this is not true despite the undeniable utopian potential of integration, connectivity, and mobilization of people, as well as the availability of space for political activity, as pointed out by Adorno and Horkheimer (1985). Social networks are formed by autonomous participants, who expose ideas and personal assets to share values and interests. Diversity and the massive public allow each user to publish any information without commitment to the truth.

According to Siegel (2008), the supporters of cyberculture (like Lévy, 1999) argue that we are moving into the era of demassification because we would be able to make our own choices and build our personalities freely. But Siegel (2008) states that what is being created is an even more potent form of homogenization. This author affirms that it is a fallacy that we are moving from passive recipients to becoming independent content producers just because we can now share our ideas and images with people through the new media in Social Networks. People are making their private moments accessible on social media.

On online social networks, people produce mostly "images", which are copies of information in various formats, manipulated by applications that distort its original appearance (for example, a text or an edited picture/photo, a video clip without the credits) (Santoro, 2017). The problem is not the manipulation itself, but that information is "sold" as the original. The viral propagation of such images causes their new meaning to be taken as truth, meanwhile, the real meaning associated with them becomes lost. The "truth" does not seem to be a tonic in the networks; people tend to talk about what makes them more popular and assume positions guided by the recommendations of the systems. Social Networks usually deliver an overflow of recommendations. In general, people spend interacting with each other and with systems over the Internet, simultaneously providing information about their profile. Targeted information sets the minds of potential consumers not only with products but also, with ideas and ways of acting and thinking. Advertising is increasingly tangled with information. The social networks offer suggestions of your best moments in the past, who your best friends are, and can associate your profile with animals, games, music, etc. In addition, it can emphatically suggest the form of joining a protest or become supportive of a social problem, according to the design previously made from people's information.

The application of statistics and computational techniques of classification has reached a remarkably high degree of sophistication, endorsing a sense of belonging (or non-belonging) of a person to specific groups. The next step is the recommendation of consumption (Kohn and Moraes, 2007). Then the cycle closes.

According to Rüdiger (2011), another danger of cyberspace is to promote an abandonment of concerns with physical reality: lost in the hybrid and strange world of the network, we may believe that virtual homes are real, that a reported clash is not different than a real one, that virtual sex is no less viable than the thing itself (Slouka, 1995). The inhabitant of the cities can only get to know friends in the online social networks. Thus, the strong impact of the Internet and social media seems to be that technology gets mixed up with way of life, and systems can capture human behavior quickly.

\subsection{The Spread of Artificial Intelligence}

Artificial intelligence (AI) is a research field whose focus is the development of computational methods and artifacts that possess or multiply the rational capacity of human beings to solve problems, to think or, in general, to be "intelligent". But what exactly do we call "artificial intelligence"? We separate it into two parts: "artificial" and "intelligence". The first one is related to what a human can construct, i.e., the artifacts. The second one refers to concepts such as consciousness, identity, and mind. Consciousness is one of the most complex mental processes which we judge to be the human's differential. Consciousness is the state of being conscious; the perception of oneself, her/his thoughts and what exists around her/him.

The growth of AI began shortly after World War II with the paper "Computing Machinery and Intelligence" by the famous English mathematician Alan Turing, and the name "Artificial Intelligence" was coined in 1956 (Berkeley, 1997). However, this idea is not recent. Aristotle, the Greek philosopher born in $384 \mathrm{BC}$, already thought of replacing the slave labor force with autonomous objects. The development of this proposal began to take shape in the 1950s, with the scholars Herbert Simon and John McCarthy. Since then, the foundations of AI have been supported by diverse disciplines, such as Philosophy, Mathematics, Economics, 


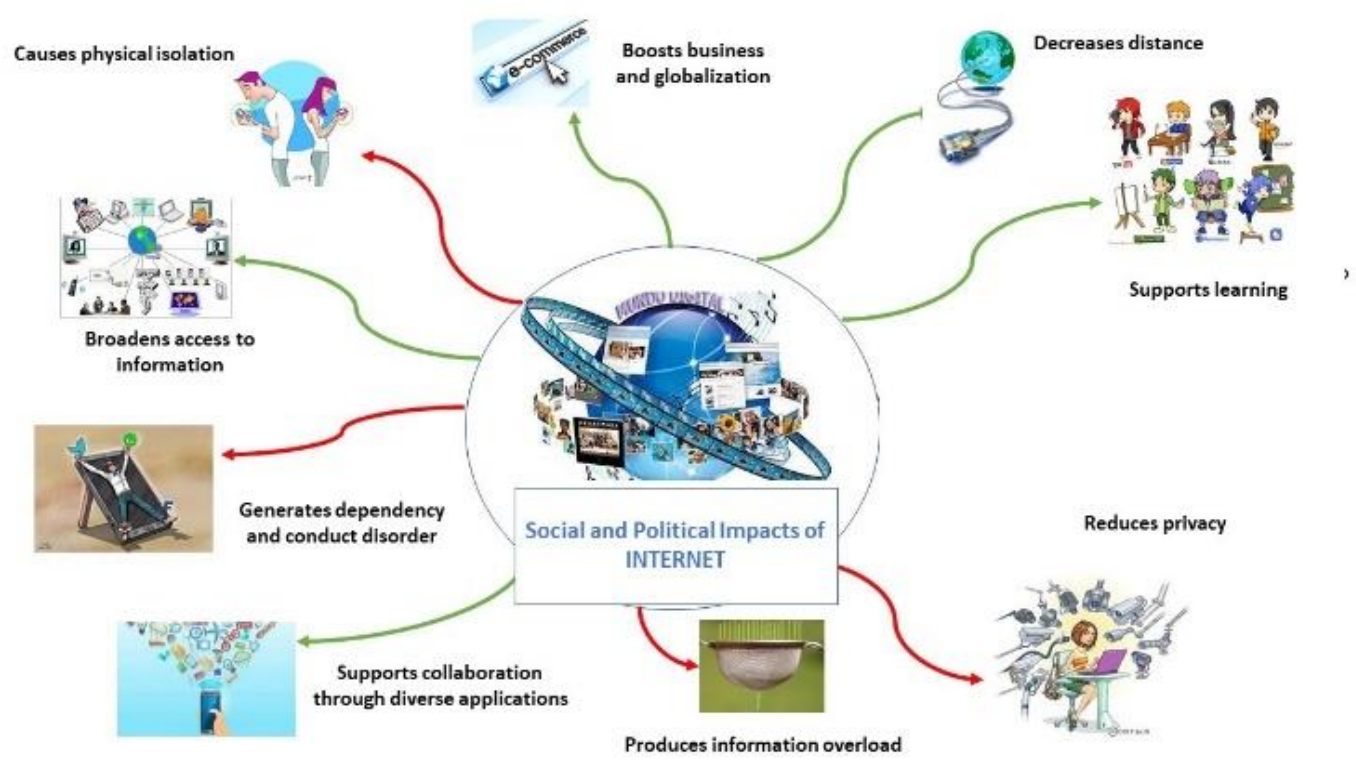

Figure 1. Social and political impact of Internet.

Psychology, and Linguistics, which have contributed with ideas and techniques. Only recently, the emergence of the modern computer made AI gain critical mass and allowed the development of applications to establish themselves and advance in areas such as computer vision, speech analysis and synthesis, fuzzy logic, artificial neural networks, and many others.

Nevertheless, we observe several negative issues related to AI, such as unemployment generated by the substitution of labor by autonomous machines; changes in human behavior and interpersonal relationships; possible mistakes made by autonomous machines that may be fatal to humans; risks of autonomous weapons; uncertainty that AI may one day surpass human capabilities and intelligence; and hesitation about the interaction between humans and robots. Figure 2 illustrates the benefits and problems related to Artificial Intelligence (AI) and its applications. The contrasts showed through arrows green and red express how AI can simultaneously support complex problem solving and promote learning but also generate unemployment and offers risks as well as uncertainty to humans' lives.

According to Miguens (2000), philosophers have been taking extreme positions about AI. Some of them argue for an impossibility, by principle, of creating unnatural intelligence and consciousness. Others are convinced that AI could create a more general and abstract concept of the nature of intelligence, which places humans and all intelligent biological beings as only particular cases of a general phenomenon. Basically, if any system with the right kind of functional organization can be intelligent, and even conscious, and whether this condition can be formulated independently of the substance that constitutes it and its origins, then those systems may be intelligent and conscious as well.

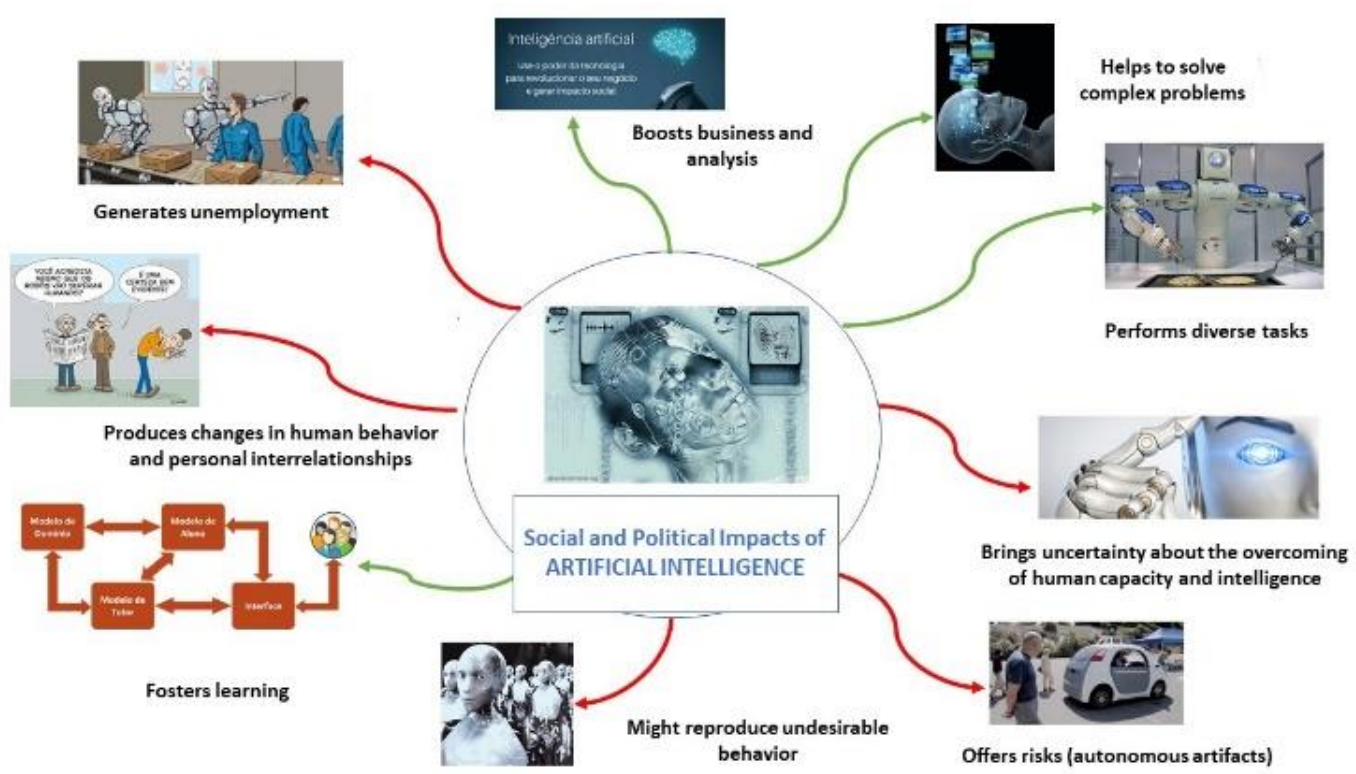

Figure 2. Social and political impact of IA. 
In 2015, the physicist Stephen Hawking, and the entrepreneurs Elon Musk (founder of Tesla and SpaceX), Steve Wozniak (co-founder of Apple), and Bill Gates (cofounder of Microsoft) signed an open letter with concerns about artificial intelligence (Wikipedia, 2015). That letter was not intended to deny the development of research in the field of AI, but it draws attention to the dangers of developing something so powerful and promising without paying attention to the generation of benefits for humanity and intrinsic ethical issues.

\subsection{Big Data or Big Brother}

The term Big Data is usually associated with a large set of stored data. From the technical point of view, the challenges of this area include analysis, capture, repository creation, and development for this data, research, sharing, storage, transfer, and visualization (Chen and Zhang, 2014). But some characteristics differentiate this data from any other else. They are called the 5 V's: velocity, volume, variety, veracity, and value. Big Data is a recent term, but the idea is quite old. By 3500 BC, the bureaucrats of ancient Mesopotamia created writing because they had to register and maintain control of commercial transactions. MayerSchonberger and Cukier (2013) argue that the invention of written language allowed early civilizations to record facts about reality to be retrieved later. These facts were the embryo of tailoring a phenomenon to a quantified format to be tabulated and analyzed.

$\mathrm{Wu}$ et al. (2013) argue that according to an IBM survey, 2.5 billion bytes of data are created every day, and 90 percent of the data in the current world was produced in the past two years. Our data-generating capacity has never been so powerful. One example is Instagram, purchased by Facebook in 2012. Nowadays, more than 95 million photos and videos are shared on Instagram per day (Omnicore,2021). Assuming the size of each photo is 2 megabytes $(\mathrm{MB})$, it results in several terabytes (TB) of air-storage every day. Since "a picture is worth more than a thousand words", the billions of Instagram photos are a treasure to explore human society opening new possibilities to explore complex relationships and data evolution, considering distributed and decentralized control (Wu et al., 2013).

Chen and Zhang (2014) point out that there is no doubt that future advances in productivity and business technologies will converge on Big Data's assets. Currently, some areas involve Big Data problems, ranging from the global economy to social administration and scientific research to national security. Big Data has a deep relationship with e-Science that is computer-intensive science, generally implemented in distributed computing systems (Kee, 2015). E-Sciences include particle physics, bioinformatics, earth science, and social simulations.

The benefits of Big Data applications in society have already been understood. However, what are the "problems" or points of attention with this promising technology? Figure 3 illustrates the benefits and issues related to Big Data and its applications. Misuse and unwanted use of data are contrasted to fostering of science and supporting decision-making by the arrows green and red in this figure. Mayer-Schönberger and Cukier (2013) warn that when data is collected passively, while people do what they usually do anyway, the old biases associated with sampling seem to disappear. Now we can collect the information we could not do before, being it the relationships among people revealed through cell phone calls or the sentiment and feelings disclosed through millions of tweets shared every day.

In this paper, we claim that more than technical advantages and disadvantages, or benefits versus adversities, the problems that arise from those technologies are related to ethics. Thus, in the next section, we propose an objective way to deal with ethical issues that might evolve within the development and usage of such technologies.

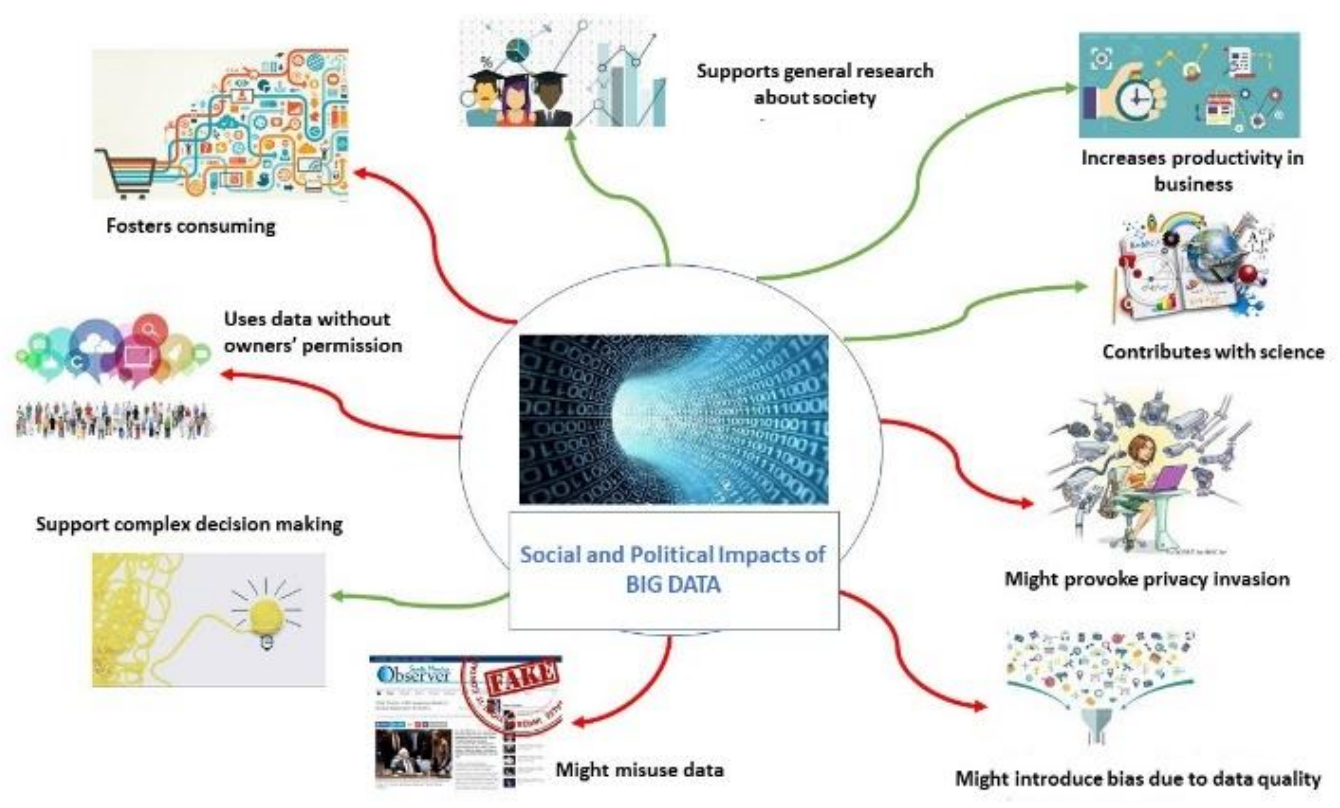

Figure 3. Social and political impact of Big Data. 


\section{Related Work}

Ethical Decision-Making Models (EDMM) are a critical part of ethics. One crucial issue concerning such models is the assumption of one area of Normative Ethics. For example, virtue ethicists concentrate on ethical people's characteristics as the primary cause of decision making, but they also consider the consequences or reasons behind the decision. A consequentialist would focus on the outcomes of decisions. Different ethical decisionmaking models have been proposed both by researchers and practitioners as described by Whittier et al. (2006), Cottone and Claus (2000), and Casali and Perano (2021).

Well-known models are complemented with principles on how to perform the steps. The PLUS Decision-Making Model $^{1}$, developed by the Ethics and Compliance Initiative (ECI), applies ethics filters to determine if the ethical components of the decision were addressed: $\mathrm{P}=$ Policies Is it consistent with my organization's policies, procedures and guidelines?; $\mathrm{L}=$ Legal Is it acceptable under the applicable laws and regulations?; $\mathrm{U}=$ Universal Does it conform to the universal principles/values my organization has adopted?; $S=$ Self Does it satisfy my personal definition of right, good and fair? Those filters support the steps proposed for the decision-making process. Step 1, define the problem; Step 2, identify available alternative solutions to the question; Step 3, evaluate the identified alternatives; Step 4, make the decision; Step 5, implement the decision; Step 6, assess the decision.

Baker and Martinson (2001) proposed the TARES model, which stands for five embedded principles: Truthfulness, Authenticity, Respect, Equity, and Social Responsibility. Those principles together should guide the actions of the decision-making process. with an ethics-related extension would undermine the essence of it and would our proposal.

Finally, Laudon and Laudon (2020) suggested steps on how to discuss the ethical issues in Information Systems, which can be particularly useful in practice: to identify and clearly describe the facts; define the conflicts or dilemma and identify the values involved; identify stakeholders; identify reasonable alternatives to be adopted and identify potential consequences of the options.

The models proposed have much in common, but we observe that despite Laudon and Laudon (2020), none of them are closely related to the IS field. In turn, Laudon and Laudon (2020) are not concerned with philosophical principles and they do not provide guidelines on how to ground the decisions on ethics. Thus, in this paper, we propose a process model that extends Laudon and Laudon approach by incorporating the guidance to use some of those principles.

\section{A Process to Support the Analysis of Ethical Issues}

As discussed in the previous sections, considering the benefits and threats of using any new technology to develop and use IS, it is fundamental to stress some ethical discussions. We extended, adapted, and detailed how each step of Laudon and Laudon (2020) approach could be performed, including two more steps. The proposal is described in detail as follows.

Our main goal is to support decision-making as well as to promote group discussions. Thus, we propose a process to organize ideas, analyze and decide about an ethical issue related to the use and adoption of IS. Figure 4 shows the process formally represented in a BPMN ${ }^{2}$ (Business Process Modeling and Notation) diagram.

A. Identify and clearly describe the facts: The correct view of a situation might help find a solution. So, the first step is looking for safe sources to find out who did what, when, and how. For avoiding biases, it is preferable to collect facts from diverse sources and confront them.

B. Define dilemma: Dilemma is a situation in which a hard choice has to be made between different possibilities. After understanding the facts, it is critical to recognize the conflicts (the dilemma) and identify the values involved: an ethical issue encompasses opposing directions of action concerning significant value (e.g., freedom, privacy, property protection, etc.).

C. Identify stakeholders: To classify the likely interests, this step suggests generating a list of stakeholders. Stakeholders might be associated with different groups of the society, for example, citizens, educational institutions, industry. However, a stakeholder could also be an individual: the owner of a company, a designer, a student, etc. Different stakeholders will have their views on the problem, and they will argue for their interests whatever they are. Some of them are probably related to ethical issues.

D. Identify alternatives: Alternatives are different implementations that might address the problem. Since we are discussing questions related to the adoption or use of IS, alternatives are varied designs of the IS or the diverse adoption processes of the IS. This step identifies reasonable alternatives to be followed (which will not always satisfy all stakeholders' requirements). At this point, the alternatives could be related (in fact, it is fundamental that they are) to distinct mental models.

E. Identify consequences: Each alternative implies consequences. Identify the potential outcomes of the options (listed in the previous step) is asking yourself what 
would happen over time with each choice. This step requires envisioning more than the intended use of the technology but also the unintended ones. At this point, it might be convenient to search for similar cases.

F. Adopt position: The conclusion of deliberation on an ethical issue should use all the elements collected and produced in previous steps and finally decide to adopt a position. At this point, it would be positive to take as a base one or more philosophical principles. In the philosophical sphere, principles, while governed by moral laws, are values that the individual considers adopting according to what his/her conscience says. Some examples are Idealism, Realism, Pragmatism.
For the idealist, goodness is found in perfection in immaterial or idea of something; and evil is the ideal distortion. Therefore, ethical imperatives can never change. Idealists judge the action itself and not its consequences. A philosopher of this line is Immanuel Kant (categorical imperative):

- How to establish a modern foundation for ethics that is both timeless and universal (always valid everywhere)?

- If an action is not right for everyone, then it is not right for anyone.

- If everyone did that, could the organization or society survive?

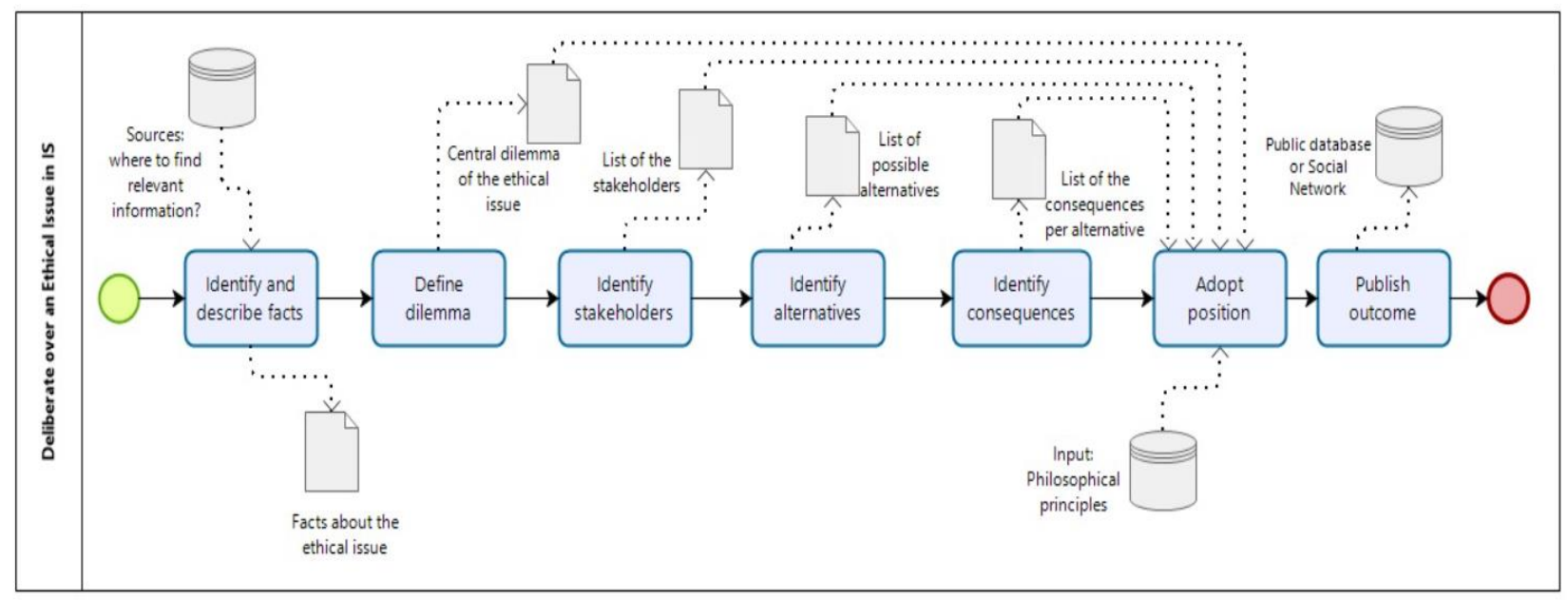

Figure 4. A process for deliberation on ethical issues.

For the realist, all knowledge is obtained through the senses. Kindness is found by living a life of virtue in harmony with nature. A philosopher who represents this line is John Locke (liberalism):

- In a natural state, man is governed by the laws of nature where all are equal, and no individual should harm another. A person has the right to use force to defend his rights, but he cannot harm the rights of others.

- Your right ends when the others' rights begins.

For the pragmatist, reality is a process, change. Event, that is, experience. The value of something is determined solely in terms of its usefulness in achieving an end. Therefore, the end justifies the means. A philosopher who exemplifies this line is Jeremy Bentham (utilitarianism):

- Principle of Utility: the action with "greater ethical value" is that one that maximizes general happiness and minimizes pain; the calculation that seeks the biggest benefit for the greatest number of people (maximizing pleasure)

- Take the action that produces the best cost / benefit ratio.
G. Publish the outcome: Sharing both the discussion and the outcome with diverse groups of society is vital for promoting changes. Thus, the whole process should be published in a repository or on Social Networks. This allows to collect and compare decisions to support the definition of public policies.

In the next section, we evaluate preliminary the application of this process in two scenarios.

\section{Case Studies}

In this section, we discuss the proposed process in two real cases.

\section{1 "Edward Snowden" Case}

This case occurred in the United States and was widely publicized in the media, as well as presented in documentary and movies. Through this case, we show how to use the process in a debate over one of the most controversial contemporary themes: Privacy vs. Security, from the point of view of ethics related to the information systems.

When Edward Snowden ${ }^{3}$, a former collaborator of the National Security Agency (NSA) in the US, disclosed a

\footnotetext{
3 The information is available at: https://pt.wikipedia.org/wiki/ Edward _Snowden
} 


\section{A. Identify and clearly describe the facts:}

The sources of fact-finding in this case are newspapers and magazines (such as The Guardian, New York Times, etc.) and trusted Internet sites (e.g., Wikipedia).

Identified facts:

- Edward Snowden was an NSA employee.

- Edward Snowden released a confidential mass monitoring program, which was confirmed by the agency.

- The program intercepts people's communications by e-mail, voice, video, facsimile and any other means of communication anywhere in the world and collects data about them.

- The program uses techniques such as computer intrusion, breaking security codes, etc.

- The program uses tools that interpret this data to determine profiles.

- The purpose of the program is to ensure safety, but nothing prevents it from being used for other purposes.

\section{B. Define dilemma:}

The central dilemma (or ethical question) posed in this case can be defined as: Should the technology be applied to break the privacy of citizens in order to provide them with protection?

\section{Identify stakeholders:}

The stakeholders in this case are citizen, US government, former NSA service provider (IS professional), technology companies, society in general.

\section{Identify alternatives:}

How to solve this case? The alternative actions (not exhaustive) would be:

[1] Nothing to do, allow the government or any company to carry out these programs.

[2] Prohibit this type of program.

[3] Allow the program, but in a transparent way to the citizen.

[4] Create a new program that has access to data already available in traditional systems only.

\section{E. Identify consequences:}

For each possible action, the consequences (not exhaustive) would be:

[1] Nothing to do, allow the government or any company to carry out these programs.

- Tolerate misuse of private information.

- Create precedents for abusive invasion of privacy actions.

[2] Prohibit this type of program.

- Restrict preventive actions about demands of the citizen and society security.

[3] Allow the program, but in a transparent way to the citizen.

- Tolerate misuse of private information.

- Create precedents for abusive invasion of privacy actions.

[4] Create a new program that accesses data already available in traditional systems only

- Restrict preventive actions about demands of the citizen and society security.

- Allow the citizen to decide on the use of his/her private information.

\section{F. Adopt position:}

Now, with all the data about the case at hand, we can evaluate it grounded on one (or more) philosophical principle to support in the decision. Let us try 2 principles.

[1] Idealism: Thinking with the support of the idealistic foundation, we would ask the following questions regarding each action: Is this action correct for all people involved? If everyone performs this action, could the society be sustainable?

The answer to those questions is probably no.

[2] Pragmatism: Thinking with the support of the pragmatic foundation, we would make the following reasoning: choose the action that produces the best cost/benefit ratio for the majority of those involved.

The answer to this question is "Allow the program, but in a transparent way to the citizen" that is finally the decision made.

\section{G. Publish the outcome: report the results and publish} a paper.

Box 1. Summary of the process to analyze ethical issues applied to the "Edward Snowden" case.

confidential mass monitoring program, the people asked: "Is he a patriot or a traitor?" which leads immediately to the following question: "What is most important for society: security or privacy?" The answer to the first question depends on the value people give to civil disobedience. The answer to the second one depends on how this value system weighs security versus privacy.

It is no doubt an ethical problem. But the further revelations also raised a question about ethics for which the answer may be more direct: "Should the government use telephone records to spy on millions of Americans and lie about it?" Or, in other words, "How transparent should the US national security state be?" For sure, this is valid for any other country.

By that time, the fact that the United States has been operating monitoring and surveillance systems for electronic communications around the world became public. Global surveillance programs have several goals and capabilities, including intercepting communications by email, voice, video, facsimile, and any other means of communication 
anywhere in the world. Since then, the disclosures have become more alarming every day and have provoked a reaction in every country in the world and the Internet protection experts' community. They range from participating in surveillance programs of companies such as Google, Facebook, Microsoft, to the worldwide invasion of computers (in the same way that the hackers do) and breaking the Internet's encryption codes, making the whole network vulnerable to the attacks both by the NSA or predators and criminals.

The US government argued that this data refers exclusively to the metadata of phone calls, not the content of the calls themselves. Metadata resembles the "envelope" of a phone call or an email but contains more detailed information than just the recipient and sender with their addresses. This metadata has no specific information about the communication, such as emails, phone calls, or textual messages. However, metadata informs in detail, for example, destination, the duration of a call, date, location of the origin from where started the communication, user location who initiated and the recipient, type of computer or telephone used, etc. Such information is enough to provide a different kind of analysis.

After the first publications in the press, technology experts and civil rights advocates right away warned that the White House underestimated the importance of metadata. However, it contains detailed information about the individuals' lives, and it could be used to draw relationships and personal activities.

We applied the process proposed in Section 4 to analyze the ethical issue in this case. We present the summary of the step-by-step process in Box 1.

\section{2 “API Exposure Notification" Case}

In 2020, the world was disturbed by the pandemic of Covid 19, a disease provoked by one type of Coronavirus. During the pandemic, the Brazilian government (following actions of other countries such as Germany, the United Kingdom, and Uruguay) announced the launching of the new functionality of its Coronavirus-SUS application. The API Exposure Notification ${ }^{4}$ would alert a registered citizen, by cell phone, within 24 hours, about people who tested positive for Covid-19 and have been close to her/him in the last 14 days. The argument for using this application was based on the fact that monitoring is fundamental for disease control and safe resumption of activities. The technology is called "API Exposure Notification" and was made available through a partnership between the Ministry of Health, Google, and Apple.

The Ministry of Health published on its website that "Exposure Notification System was built so as not to expose the identity of users, such as name and location, ensuring maximum security and privacy for all data". The feature allows that the citizen, voluntarily and anonymously, to inform the application of the positive result for Covid-19, using a token (code of numbers) issued by the Ministry of Health - the validation of their test (PCR or positive ${ }^{5}$ ) for the disease. To avoid false information, before generating the token, the Ministry of Health would cross data from the examination informed by the person and the integrated records of the surveillance platform (e-SUS Notifica) and the National Health Data Network (RNDS). Both databases gather information from patients with Covid-19 in Brazil. With the encrypted transmission of contagion information, using the low-energy Bluetooth, the Coronavirus-SUS application recognizes close contacts at 1.5 to 2 meters and for a minimum of five minutes between smartphones that have the application. To receive notifications of close contact with positive users for Covid-19, it is necessary that the user enable the exposure notification function on the device. The app works only with other people that have also the official app installed. The notification will be sent only by the Ministry of Health. The user will receive information that they have had possible contact with someone who tested positive for Covid-19 in the past hours.

The Ministry of Health guarantees that no other institution will have a license to use the functionality developed by Google and Apple. The application works without tracking the tester's movements, and without knowing his identity or the identity with whom he came into contact. Besides, it does not have access to any personal information, and no geolocation data is collected. All data is encrypted, saved locally on the smartphone, and is only available for 14 days.

Despite all the legal guarantees, the genre of the system probably allows the government to initiate a program of control and monitoring of citizens. We applied the process proposed in Section 4 to analyze the ethical issue in this case. The summary is presented in Box 2.

\section{Discussion}

In Section 2, we explore some of the most relevant technologies highlighting how they impact our society (Internet applications, AI and Big Data), and in Section 4 , we propose a process to examine some associated ethical issues. In the end, the general question is: "Do artifacts have underlying politics?"; "Do artifacts imply a certain organization of power and authority?" Mumford (1963) emphasized that the technical activity innate in human life was gradually subordinated to social and political devices, products of the subjection of the masses to the power of the elites. The philosophers of the Frankfurt School (Horkheimer, 1982) criticized how an industrial society with scientific and technological bases constitutes a system of domination of man by man. Levy (1993) has already warned that there is no computing in general, but rather an open, conflictive, and partly indeterminate field of new technologies.

4 https://www.saude.gov.br/noticias/agencia-saude/47292-aplicativocoronavirus-sus-vai-alertar-contatos-proximos-de-pacientes-comcovid-19

5 PCR is a test that detects the presence of the virus in a blood sample. 


\section{A. Identify and clearly describe the facts:}

The sources of fact-finding in this case are newspapers and magazines (such as O Globo, Folha de São Paulo, etc.) and trusted Internet sites (e.g., Olhar Digital ${ }^{6}$ ). Identified facts:

- Brazil will officially begin to use geolocation data to study and try to contain the coronavirus.

- The five main mobile phone operators (Algar, Claro, Oi, TIM and Vivo) confirmed that they started to provide data on the users' position to the Ministry of Science, Technology, Innovations and Communications (MCTIC), which can provide these information for all spheres of public power.

- Brazil is far from being the first to adopt such a measure. The greatest example of a country that is ostensibly using this data is South Korea. There, when someone is diagnosed with the coronavirus, the government tries to track down all the people who have passed close to the patient and notifies them with a message.

- There is evidence that other countries that started with this type of monitoring may broaden its use. Inspired by the application created to control the pandemic, the Chinese city of Hangzhou has announced that it plans to use a system that gives citizens a personal score based on their medical report, health checks and lifestyle. The announcement sparked controversy, raising concerns about the privacy of the inhabitants?

\section{B. Define dilemma:}

The central dilemma (or ethical question) posed in this case can be defined as: Should an application be built with the aim of monitoring citizens?

\section{Identify stakeholders:}

The stakeholders in this case are citizen, Brazilian government, mobile phone operators, technology companies (Apple, Google), society in general.

\section{Identify alternatives:}

How to solve this case? The alternative actions (not exhaustive) would be:

[1] Nothing to do, allow the government or any company to develop and use the application.

[2] Prohibit this type of application.

[3] Allow the development of the application, but in a transparent way to the citizen.

E. Identify consequences:

For each possible action, the consequences (not exhaustive) would be:

[1] Nothing to do, allow the government or any company to develop and use the application.

- Tolerate misuse of private information.

- Create precedents for abusive monitoring of citizens.

[2] Prohibit this type of application.

- Restrict preventive actions about demands of the citizen and society health.

[3] Allow the development of the application, but in a transparent way to the citizen.

- Tolerate misuse of private information.

- Create precedents for abusive monitoring of citizens.

- Allow the citizen to decide on the use of his/her private information.

\section{F. Adopt position:}

Now, with all the data about the case at hand, we can evaluate it grounded on one (or more) philosophical principle to support in the decision. Let us try the realism principle.

[1] Realism: Thinking with the support of the realist foundation, we would ask the following questions regarding each action: are the rights of one citizen being violated on the behalf of the others?

The answer to this question is probably no.

G. Publish the outcome: report the results and publish a paper.

Box 2. Summary of the process to analyze ethical issues applied to the "API Exposure Notification" Case.

Managers and engineers recognize that winning strategies bear minimal technical details but are primarily political and cultural. In both cases presented, we could only get attained to the technical perspective, i.e., how to implement the program or the requirements to build the application. Then we might conclude that they are perfectly implementable technologies, and the user will be safe. However, the ethical issues go over them because it is fundamental to put a wider lens on the problem considering other tools.

Accordingly, we wonder whether the only form of rigorous and helpful reasoning is scientific and technological or if there may be non-technical forms of reasoning applicable to social issues and day-to-day problems. Is it possible for the ordinary man, who does not participate in its design, to decide and control technology? Our proposed process aims to be a starting point for this debate.

Feenberg (2013) proposed a Critical Theory of Technology and argued that technology is controllable and valuable. Technology can shape many possible different lifestyles, reflecting choices of goals and mediation. For this author, the values embodied in technology are characteristic of a society. Modern societies aim for efficiency; however, we cannot neglect other significant valuations besides it. The author explains that it is impossible not to differentiate efficient weapons from efficient medicines, efficient 
propaganda from efficient education, efficient exploration from efficient research. The Critical Theory of Technology allows us to think about choices and submit them to democratic controls. The conclusions obtained from the two case studies indicate that it is important to add elements surrounding the technical problem, such as the social and political facts. Following a systematic process that, not only calls the attention to the importance of colleting facts, but also states that philosophical principles should be applied confirmed the potential of reflecting of such choices that Feenberg mentions.

Feenberg (2013) does not believe in the notion of technology neutrality. The author does not consider technology an autonomous entity, but rather the manifestation of political rationality. Thus, it can only be modified through cultural changes and democratic advances. The Critical Technology Theory considers technology as an environment rather than a collection of tools. As an environment, technologies shape the lives of its inhabitants, being comparable to laws and rights. In addition, the adaptation process of social institutions to technological development is reciprocal, i.e., institutions adapt while technologies change in response to the conditions they find. In this regard, the systematization of ethical discussion would allow citizens to engage in decisions not only about what is wrong or right, but also how technology should be designed. When we organize the ideas about the adoption of technologies as shown in the two cases investigated, it is possible to shed light on this mutual path.

The main form of power has become technological, which is achieved through the strategic control of social and personal activities. Technological decisions are made according to the efficiency criterion that in turn, can be defined in diverse ways according to social interests. Feenberg identifies a social "code" of technology that blends efficiency and target and somehow legislates in our lives. Our way of life, our gestures, are programmed by our artifacts with rigidity unprecedented in pre-modern societies (Feenberg, 2009).

There is a widespread technical mediation at the service of privileged interests that reduces human possibilities everywhere, imposing discipline, vigilance, standardization in all activities (work, education, medicine, law, sports, media, etc.). Reciprocally, the mediation of some social interests turns the technological achievements abstract and decontextualized, apparently belonging to no culture. It becomes clear, for example, in second case analyzed, that even with legal guarantees, the system is likely to allow monitoring of people involved. However, according to Feenberg (2009), it is precisely the perception of these limitations that can stimulate transformative political movements. Because technology is ambivalent and can be instrumental to different political projects, every technological order is a potential starting point for divergent developments, depending on the cultural environment that configures it.

The social change suggested by the author needs progress criteria. A progressing society increases people's capacity to take political responsibility, fosters the universality of the human being, allows for freedom of thought, respects the individual, and encourages creativity. The author cites concrete measures: the democratization of public administration, the extension of the lifespan devoted to learning beyond the immediate needs of the economy, and the evolution of professional training to include an everincreasing range of human needs in the technician code.

Therefore, the various aspects of the design must be decided concerning social principles and demands. This context must be widely understood to bring technology into the public sphere, where increasingly it seems to belong. In Feenberg's proposal (2013), modern societies will only be able to recognize democratic values when the public control of technology becomes routine. The Critical Theory of Technology projects a future in which technology policy is considered as a usual aspect of public life. The design of technologies would be oriented to politically legitimized human values, as opposed to the profit intentions of military organizations or to bureaucracies. These values should be present in the technical disciplines themselves, just as the value of healing guides Medicine and knowledge of the human body guides Biology. In the two cases discussed in the of the proposed process, we could observe the relevance of considering human values embedded in the technology and more specifically, in the information systems.

Feenberg defines the Instrumentalization Theory, which seeks, on the one hand, the distinction between the cognitive and imaginative conditions of technical activity, and on the other hand, the social mediations that intervene in the design of devices and systems. Every technical artifact presupposes the ability to be perceived by the world in terms of functions and capabilities. This perception is cited by Feenberg as "Primary Instrumentalization". In this scenario, objects of technical activities are defined and isolated from their natural context through primary instrumentalization that decontextualizes them and reduces them to aspects of their use. It is a process in which objects are detached from their original contexts and exposed to analysis and manipulation, while individuals are assigned to distant control.

Technical objects can only be realized in a device or system, acquiring more and more social determinants in each stage of the production process, from the raw material to the final finished product. The sub-determined technical aspects of the object are decided along the way to adapt it to a given social context. This process of social determination is named by Feenberg as "Secondary Instrumentalization". The primary level simplifies objects for incorporation into a device, while the secondary level integrates simplified objects into a natural and social environment.

Finally, Feenberg (2013) also presents the concept of "technical code" to articulate the relationship between social and technical needs. A technical code is the concretization of interest or ideology in a technically coherent solution to a problem. A technical code is a criterion that selects between alternative viable projects, the one that presents the best technique to be applied in terms of a social objective. Objectives are "codified," in the sense of defining requirements as ethically permissible or prohibited, and/or aesthetically better or worse, or socially desirable. "Socially 
desirable" does not refer to some universal criterion, but a hegemonic value such as health or family. In this sense, Feenberg calls technical codes the social principles embedded in a technology that is successful and enduring. Specific technical codes determine the meaning of artifacts and, in any situation, describe the congruence of social demand and a technical specification.

Our proposal corroborates with the principle that the outcome of the process about an ethical issue allows the definition of IS politics and could guide the specification of the IS requirements. When people decide that transparency is a goal (such as in our case), it should be a requirement for a system to be developed.

According to Feenberg (2009) an 'alternative modernity', would recognize the power of mediation, ethics, and aesthetics at the level of technical disciplines and design, restoring power to technical net-work members rather than concentrating it at the top of administrative hierarchies. This would result in new technical designs and new ways of achieving efficiency, and its members would value the offer of quality of life, a more democratic political order, and a sustainable civilization.

Our proposal corroborates with the Critical Theory of Technology because the results obtained with the application of the proposed process are aligned with the main issues raised in this theory.

\section{Final Remarks}

Information systems should have an increasingly incisive presence in everyday activities. Argumentation on the impacts of new technologies requires theoretical and technical references. It will be up to the IS designer to intermediate the adaptation of the technology to the specificities of the diverse socio-cultural contexts. Thus, we conclude by emphasizing the fundamental role and responsibility of the designer in all these processes, for when designing new products and functionalities based on technologies such as the ones analyzed in this paper: internet, artificial intelligence, big data, or other new technologies to be developed in the future, he/she must be attentive to the so-called "technical code", as pointed out by Feenberg.

We proposed a process to address ethical discussions about IS. The steps of this process guide the individual to decide. The main contribution of this paper is the argumentation on how a process like the one proposed could support the implementation of a Critical Theory of Information Systems, as argued by Feenberg, engaging people on the dialogue about IS requirements that shape the society in which he/she is inserted.

Future work includes the evaluation of the process proposed with different groups of people and contexts. Besides, we intend to implement a tool to support the method and make it available and public to encourage the emergence of other relevant ethical questions as well as to build a repository of shared cases.

\section{References}

Adorno, T. W., Horkheimer, M. (2002). "Dialectic of Enlightenment", Trans. Edmund Jephcott, Stanford: Stanford UP.

Baker, S. and Martinson, D. L. (2001). "The TARES Test: Five Principles for Ethical Persuasion," Journal of Mass Media Ethics (16:23), p. 148-175.

Bowyer, K.W (ed) (2000). Ethics and Computing: Living Responsibly in a Computerized World. New York: IEEE Press, $2^{\mathrm{a}}$ ed.

Bunge, M. (1968). Scientific laws and rules. Contemporary philosophy: a survey. Florence: La Nuova Italia Editrice, v.2.

Bynum, T. Computer and Information Ethics. The Stanford Encyclopedia of Philosophy (Summer 2018 Edition), E.N. Zalta (ed.), forthcoming URL: $<$ https://plato.stanford.edu/archives/sum2018/entries/eth ics-computer/>.

Casali, G.L., Perano, M. (2021). Forty years of research on factors influencing ethical decision making: Establishing a future research agenda. Journal of Business Research, v. 132, p. 614-630.

Chen, C.L.P., Zhang, C.Y. (2014). Data-intensive applications, challenges, techniques, and technologies: A survey on Big Data. Information Sciences, v. 275, p. 314 347.

Cottone, R. R., Claus, R. E. (2000). "Ethical DecisionMaking Models: A Review of the Literature," Journal of Counseling \& Development (78:3), p. 275283.

Dusek, V. (2006). "Philosophy of Technology: An Introduction”, Malden, USA: Blackwell Publishing.

Feenberg, A. (2009). Democratic Rationalization: Technology, Power and Freedom, Readings in the Philosophy of Technology. Ed. Kaplan, David M. 2nd Ed. Plymouth: Rowman \& Littlefield Publishers Inc. Chap.10, p. 139-154.

Feenberg, A. (2013) Critical Theory of Technology. A Companion to the Philosophy of Technology, Part III, Chapter 24. Edited by Jan Kyrre Berg Olsen, Stig Andur Pedersen, Vincent F. Hendricks, Malden: Blackwell Publishing.

Heidegger, M. (2007) A questão da técnica. Tradução de Scientiæ Zudia, São Paulo, v. 5, n. 3, p. 375-98.

Horkheimer, M. (1982). Critical Theory Selected Essays, New York: Continuum Pub.

Kee, K. F. (2015). Three critical matters in big data projects for e-science: Different user groups, the mutually constitutive perspective, and virtual organizational capacity. In 2015 IEEE International Conference on Big Data, p. 2091-2097.

Kohn, K., Moraes, C.H. (2007). O impacto das novas tecnologias na sociedade: conceitos e características da Sociedade da Informação e da Sociedade Digital. XXX Congresso Brasileiro de Ciências da Comunicação, Santos, 2007. 
Laudon, K. Laudon, J. (2020). Management Information Systems: Managing the Digital Firm, 16th ed. New York, NY: Pearson.

Levy, P. (2001). Cyberculture. University of Minnesota Press.

Masieiro, P.C. (2001) Ética em Computação. São Paulo: EDUSP.

Mayer-Schönberger V, Cukier K. (2013). Big Data: A Revolution That Will Transform How We Live, Work, and Think. Boston, MA: Houghton Mifflin Harcourt.

Miguens, S. (2000) Alguns problemas de Filosofia da IA, Intelecto, Revista de Divulgação Filosófica online, vol. 3.

Moor, J.H. (1985). What is Computer Ethics. Metaphilosophy, v. 16, no. 4.

Moor, J. H. (2020). The Mature, Importance, and Difficulty of Machine Ethics. In Machine Ethics and Robot Ethics, p. 233-236. Routledge.

Mumford, L. (1970). The myth of the machine. New York, H.B. Jovanovich, 2 vols.

Omnicore (2021). Instagram by the Numbers: Stats, Demographics \& Fun Facts, URL: https://www.omnicoreagency.com/instagram-statistics/, visitado em abril 2021.
Rüdiger, F. (2011). Cultura e cibercultura: princípios para uma reflexão conceitual crítica. Logos (UERJ), n. 34, p.42-61 (in Portuguese).

Santoro, F. M., Costa, R. M. E. M. (2020). A Process to Analyze Ethical Issues of Information Systems. In Anais do I Workshop sobre as Implicações da Computação na Sociedade-SBC, p. 25-36.

Santoro, F.M. (2017) Information Technology in the Internet Era: Critical Theory Perspective. In: 23rd Americas Conference on Information Systems, Boston.

Siegel, L. (2008). Against the machine. Nova York: Spiegel \& Grau.

Slouka, M. (1995). War of the worlds. Nova York: Basic Books.

Wikipedia, (2015) Open Letter on Artificial Intelligence. URL:<https://en.wikipedia.org/wiki/Open_Letter_on_Ar tificial_Intelligence>, last access: April 2021.

Whittier, N., Williams, S., Dewett, T. (2006). Evaluating ethical decision-making models: a review and application. Society and Business Review (1:3), pp. 235-247.

Wu, X., Zhu, X., Wu, G.Q, Ding, W. (2013). Data mining with big data. IEEE Transactions on Knowledge \& Data Engineering, v. 26, no. 1, pp. 97-107. 